\title{
Review of: "Production of hydrogen peroxide in an intra-meander hyporheic zone at East River, Colorado"
}

\author{
Patricia Elizabeth Garcia
}

Potential competing interests: The author(s) declared that no potential competing interests exist.

This study examines the hydrogen peroxide $(\mathrm{H} 2 \mathrm{O} 2)$ production in three different compartments of the river: intra-meander hyporheic zone, wells close to meander and in a seep. A 7 points transect in the hyporheic zone was used, in this sector four measures including H2O2, ORP, DO and DOC were performed. The results showed the highest $\mathrm{H} 2 \mathrm{O} 2$ concentration near the river zone, positively correlated with the ORP. Interestingly, in the same transect, DO and Fe (II) showed opposite trends. The authors explain this patters as a combination effect: when $\mathrm{O} 2$ in move to the center of meander is rapidly consumed with the increase in Fe(II). The oxidation of reduced transition metals, in this case Fe (II) could in turn reduce the formation of $\mathrm{H} 2 \mathrm{O} 2$.

In all the sampled compartments, the $\mathrm{H} 2 \mathrm{O} 2$ production showed a diel pattern, suggesting that the $\mathrm{H} 2 \mathrm{O} 2$ photo-production is the main pathway. The authors also associated the $\mathrm{H} 2 \mathrm{O} 2$ production with the presence of organic matter, although no further characterization of the dissolved organic matter was performed. Finally, the authors state that $\mathrm{H} 2 \mathrm{O} 2$ production will depend on the local redox conditions, this redox conditions as been underestimated in the past, but the oxidation seems to drive biogeochemical process including the carbon cycling and the metal's availability. 